\title{
Progress Toward Hepatitis B Control and Elimination of Mother-to-Child Transmission of Hepatitis B Virus - Western Pacific Region, 2005-2017
}

Joseph Woodring, $\mathrm{DO}^{1}$; Roberta Pastore, $\mathrm{MD}^{1}$; Anne Brink, $\mathrm{MBBS}^{2}$; Naoko Ishikawa, MD, PhD²; Yoshihiro Takashima MD, PhD ${ }^{1}$; Rania A. Tohme MD 3

Hepatitis B vaccine (HepB), which has been available since 1982, provides lifelong protection against hepatitis B virus (HBV) infection and the associated 20\%-30\% increased lifetime risk for developing cirrhosis or hepatocellular carcinoma among $>95 \%$ of vaccine recipients (1). Before HepB introduction into national childhood immunization schedules, the estimated hepatitis B surface antigen ( $\mathrm{HBsAg}$ ) prevalence in the World Health Organization (WHO) Western Pacific Region (WPR)* was $>8 \%$ in 1990 (2). In 2005, the WPR was the first WHO region to establish a hepatitis B control goal, with an initial target of reducing HBsAg prevalence to $<2 \%$ among children aged 5 years by 2012. In 2013, the WPR set more stringent control targets to achieve by 2017 , including reducing $\mathrm{HBsAg}$ prevalence to $<1 \%$ in children aged 5 years and increasing national coverage with both timely HepB birth dose (HepB-BD) (defined as administration within 24 hours of birth) and the third HepB dose (HepB3) to $\geq 95 \%$ (3). All WPR countries/areas endorsed the Regional Action Plan for Viral Hepatitis in the Western Pacific Region 2016-2020 in 2015 (4) and the Regional Framework for the Triple Elimination of Mother-to-Child Transmission of human immunodeficiency virus (HIV), Hepatitis B and Syphilis in Asia and the Pacific 2018-2030 (triple elimination framework) in 2017 (5). These regional targets and strategies are aligned with program targets established by the WHO Global Health Sector Strategy on Viral Hepatitis 2016-2021 that aim to reduce HBsAg prevalence among children aged 5 years to $\leq 1 \%$ by 2020 and to $\leq 0.1 \%$ by 2030 (の). This report describes progress made to achieve hepatitis B control in the WPR and the steps taken to eliminate mother-to-child transmission (MTCT) of HBV during 2005-2017. During this period, regional timely HepB-BD and $\mathrm{HepB} 3$ coverage increased from $63 \%$ to $85 \%$ and from $76 \%$ to $93 \%$, respectively. As of December 2017, 15 (42\%) countries/areas achieved $\geq 95 \%$ timely HepB-BD coverage;

\footnotetext{
*The Western Pacific Region, one of the six regions of the World Health Organization, consists of 37 countries and areas with a total population of approximately 1.8 billion, including American Samoa (USA), Australia, Brunei, Cambodia, China, Commonwealth of the Northern Mariana Islands (USA), Cook Islands, Federated States of Micronesia, Fiji, French Polynesia (France), Guam (USA), Hong Kong (China), Japan, Kiribati, Laos, Macao (China), Malaysia, Marshall Islands, Mongolia, Nauru, New Caledonia (France), New Zealand, Niue, Palau, Papua New Guinea, Philippines, Pitcairn Islands (UK), Samoa, Singapore, Solomon Islands, Republic of Korea, Tokelau (New Zealand), Tonga, Tuvalu, Vanuatu, Vietnam, and Wallis and Futuna (France).
}

$18(50 \%)$ reached $\geq 95 \%$ HepB3 coverage; and 19 (53\%) countries/areas as well as the region as a whole were verified to have achieved the regional and global target of $<1 \% \mathrm{HBsAg}$ prevalence among children aged 5 years. Continued implementation of proven vaccination strategies will be needed to make further progress toward WPR hepatitis $\mathrm{B}$ control targets. In addition to high HepB-BD and HepB3 coverage, enhanced implementation of complementary hepatitis $\mathrm{B}$ prevention services through the triple elimination framework, including routine $\mathrm{HBsAg}$ testing of pregnant women, timely administration of hepatitis B immunoglobulin to exposed newborns, and antiviral treatment of mothers with high viral loads, will be needed to achieve the global hepatitis B elimination target by 2030 .

\section{Immunization Activities}

HepB-BD and HepB3 coverage data are reported annually to $\mathrm{WHO}$ and the United Nations Children's Fund (UNICEF) from 36 of the 37 WPR countries and areas. ${ }^{\dagger} \mathrm{WHO}$ and UNICEF estimate vaccination coverage for 27 countries in the region, using annual government-reported survey and administrative data; for the remaining areas and territories, government-reported coverage data are used. By 2005, all countries/areas in the region had introduced at least three HepB doses into national immunization schedules. By 2012, 34 (94\%) of 36 countries/areas provided universal HepB-BD (Table 1); since 1987, Japan and New Zealand have provided selective administration of timely HepB-BD to infants born to mothers who are $\mathrm{HBsAg}$-positive or whose $\mathrm{HBsAg}$ status is unknown. During 2005-2017, regional HepB-BD coverage increased from $63 \%$ to $85 \%$, and HepB3 coverage increased from $76 \%$ to $93 \%$. In 2017,15 (42\%) of 36 countries/areas achieved $\geq 95 \%$ timely HepB-BD coverage, and $18(50 \%)$ countries/areas reached $\geq 95 \%$ HepB3 coverage.

\section{HBsAg seroprevalence surveys}

Surveillance for acute hepatitis B infection and its sequelae cannot fully capture the population prevalence of HBV infections, because most infants and children remain asymptomatic during acute infection. Nationally representative

\footnotetext{
The Pitcairn Islands, with a population of approximately 50 persons, does not have an immunization program and does not report immunization coverage data to $\mathrm{WHO} / \mathrm{UNICEF}$.
} 
TABLE 1. Hepatitis B vaccine (HepB) schedule and estimated coverage* with a timely birth dose ${ }^{\dagger}$ and third dose of HepB, by country/area World Health Organization (WHO) Western Pacific Region, 2005, 2012, and 2017

\begin{tabular}{|c|c|c|c|c|c|c|c|c|}
\hline \multirow[b]{3}{*}{ Country/Area } & \multirow[b]{3}{*}{ HepB schedule } & \multirow[b]{3}{*}{$\begin{array}{l}\text { Year birth dose } \\
\text { introduced }\end{array}$} & \multicolumn{6}{|c|}{$\%$ Coverage } \\
\hline & & & \multicolumn{2}{|c|}{2005} & \multicolumn{2}{|c|}{2012} & \multicolumn{2}{|c|}{2017} \\
\hline & & & $\begin{array}{c}\text { Timely } \\
\text { HepB-BD }^{\dagger}\end{array}$ & НерВ3 & $\begin{array}{l}\text { Timely } \\
\text { HepB-BD }^{\dagger}\end{array}$ & НерВ3 & $\begin{array}{c}\text { Timely } \\
\text { HepB-BD }^{\dagger}\end{array}$ & НерВ3 \\
\hline American Samoa & $0,1 \mathrm{mo}, 12 \mathrm{mos}$ & 1991 & 100 & 80 & $100(2011)$ & $77(2011)$ & NR & NR \\
\hline Australia & $0,2 \mathrm{mos}, 4 \mathrm{mos}, 6 \mathrm{mos}$ & 2000 & NR & 95 & NR & 91 & NR & 95 \\
\hline Brunei & $0,2 \mathrm{mos}, 4 \mathrm{mos}, 6 \mathrm{mos}$ & 1988 & 96 & 99 & 95 & 99 & 99 & 99 \\
\hline Cambodia & $0,6 \mathrm{wks}, 10 \mathrm{wks}, 14 \mathrm{wks}$ & 2005 & NR & $82^{\S}$ & 68 & 91 & 79 & 93 \\
\hline China & $0,1 \mathrm{mo}, 6 \mathrm{mos}$ & 1992 & 86 & 84 & 96 & 99 & 96 & 99 \\
\hline $\begin{array}{l}\text { Commonwealth of Northern } \\
\text { Mariana Islands }\end{array}$ & 0, $6 \mathrm{wks}, 4 \mathrm{mos}, 6 \mathrm{mos}$ & 1988 & 99 & 89 & 98 & 76 & 95 & 71 \\
\hline Cook Islands & 0, $6 \mathrm{wks}, 3 \mathrm{mos}, 5 \mathrm{mos}$ & 1989 & 99 & 99 & 97 & 98 & 99 & 99 \\
\hline $\begin{array}{l}\text { Federated States of } \\
\text { Micronesia }\end{array}$ & 0, 2 mos, 4 mos, 6 mos & 1988 & 93 & 91 & 81 & 82 & 75 & 80 \\
\hline Fiji & 0,6 wks, 10 wks, 14 wks & 1989 & 90 & 99 & 90 & 99 & 90 & 99 \\
\hline French Polynesia & $0,2 \mathrm{mos}, 10 \mathrm{mos}$ & 1992 & 100 & 97 & $98(2014)$ & 99 & 98 & 98 \\
\hline Guam & $0,1-2 \mathrm{mos}, 6-18 \mathrm{mos}$ & 1988 & 98 & 88 & 100 & 38 & 80 & 83 \\
\hline Hong Kong SAR (China) & $0,1 \mathrm{mo}, 6 \mathrm{mos}$ & 1988 & 100 & 95 & 95 & 95 & 95 & 95 \\
\hline Japan & $2 \mathrm{mos}, 3 \mathrm{mos}, 7 \mathrm{mos}$ & $1986^{\natural}$ & $N A^{9}$ & NR & $\mathrm{NA}^{\mathrm{n}}$ & NR & NA & NR \\
\hline Kiribati & 0,6 wks, 10 wks, 14 wks & 1990 & 70 & 50 & 82 & 94 & 89 & 90 \\
\hline Laos & 0,6 wks, 10 wks, 14 wks & $2004^{* *}$ & $2^{\S}$ & 49 & NR & 79 & 55 & 85 \\
\hline Macao SAR (China) & $0,1 \mathrm{mo}, 6 \mathrm{mos}$ & 1989 & 100 & 88 & 100 & 94 & 100 & 95 \\
\hline Malaysia & $0,1 \mathrm{mo}, 6 \mathrm{mos}$ & 1989 & 90 & 96 & 91 & 97 & 90 & 98 \\
\hline Marshall Islands & 0, $2 \mathrm{mos}, 4 \mathrm{mos}, 6 \mathrm{mos}$ & 1998 & 99 & 89 & 96 & 80 & 97 & 82 \\
\hline Mongolia & 0, $2 \mathrm{mos}, 3 \mathrm{mos}, 4 \mathrm{mos}$ & 1991 & 89 & 98 & 97 & 99 & 98 & 99 \\
\hline Nauru & 0,6 wks, 10 wks, 14 wks & NK & 98 & 80 & 99 & 79 & 99 & 87 \\
\hline New Caledonia & $0,2 \mathrm{mos}, 11 \mathrm{mos}$ & NK & 99 (2007) & 99 (2006) & 98 & 93 & 98 & 93 \\
\hline New Zealand & $6 \mathrm{wks}, 3 \mathrm{mos}, 5 \mathrm{mos}$ & $1987^{\uparrow}$ & NA & 87 & $\mathrm{NA}^{\mathrm{n}}$ & 93 & $\mathrm{NA}^{9}$ & 94 \\
\hline Niue & $0,6 \mathrm{wks}, 3 \mathrm{mos}, 5 \mathrm{mos}$ & NK & 9 & 85 & 99 & 98 & 84 & 99 \\
\hline Palau & $0,2 \mathrm{mos}, 6 \mathrm{mos}$ & 1989 & 99 & 98 & 99 & 89 & 99 & 98 \\
\hline Papua New Guinea & $0,1 \mathrm{mo}, 2 \mathrm{mos}, 3 \mathrm{mos}$ & $2003^{* *}$ & $35(2006)$ & 63 & 35 & 68 & 33 & 56 \\
\hline Philippines & 0,6 wks, 10 wks, 14 wks & 2007 & NA & 49 & 39 & 88 & 67 & 88 \\
\hline Republic of Korea & $0,1 \mathrm{mo}, 6 \mathrm{mos}$ & 1983 & $98^{\S}$ & 99 & $92(2014)^{\S}$ & 99 & 92 & 98 \\
\hline Samoa & 0,6 wks, 10 wks, 14 wks & NK & 52 & 51 & 83 & 82 & 81 & 73 \\
\hline Singapore & $0,1 \mathrm{mo}, 5 \mathrm{mos}$ & 1987 & 74 & 96 & 67 & 97 & 91 & 96 \\
\hline Solomon Islands & 0,6 wks, 10 wks, 14 wks & $2005^{* *}$ & 80 & 83 & 59 & 99 & 67 & 99 \\
\hline Tokelau & 0,6 wks, 10 wks, 14 wks & 1990 & 100 & 100 & 56 & 100 & 100 & $100(2016)$ \\
\hline Tonga & 0,6 wks, 10 wks, 14 wks & 1988 & 89 & 89 & 84 & 77 & 88 & 81 \\
\hline Tuvalu & 0,6 wks, 10 wks, 14 wks & NK & 99 & 79 & 99 & 97 & 99 & 96 \\
\hline Vanuatu & $0,6 \mathrm{wks}, 10 \mathrm{wks}, 14 \mathrm{wks}$ & 1989-1990 & $92(2006)^{\S}$ & 61 & $79^{\S}$ & 79 & $75^{\S}$ & 85 \\
\hline Vietnam & 0, $2 \mathrm{mos}, 3 \mathrm{mos}, 4 \mathrm{mos}$ & 2005 & $62^{\S}$ & 94 & 76 & 97 & 77 & 94 \\
\hline Wallis and Futuna & $0,2 \mathrm{mos}, 11 \mathrm{mos}$ & 2006 & N/A & $100(2003)$ & 100 & $>100^{\S}$ & 97 & $>100^{\S}$ \\
\hline Western Pacific Region & - & - & 63 & 76 & 80 & 93 & 85 & 93 \\
\hline Global & - & - & 23 & 54 & 34 & 80 & 43 & 84 \\
\hline
\end{tabular}

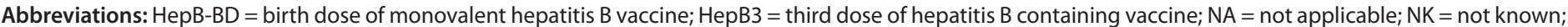
$\mathrm{NR}=$ not reported; SAR = special autonomous region; UNICEF = United Nations Children's Fund.

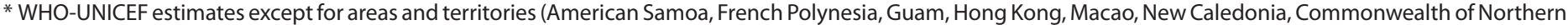

Mariana Islands, Tokelau, Wallis, and Futuna), and where otherwise specified.

† Timely hepatitis B birth-dose is defined as administration of a dose of hepatitis B vaccine within 24 hours of birth.

$\S$ WHO-UNICEF estimates not available; reported coverage used instead.

१ Year of introduction of selective birth dose vaccination of newborns of mothers who are HBsAg positive or of unknown HBsAg status.

** Approximate year of birth dose introduction into the routine immunization program.

HBsAg seroprevalence surveys allow countries to assess the prevalence of chronic HBV infection among children born after the introduction of hepatitis $B$ vaccine in the national immunization schedule and track progress toward achievement of regional hepatitis B control targets. In 1990, before HepB was introduced into childhood immunization schedules in most WPR countries/areas, HBsAg seroprevalence among children aged 5 years was estimated to be $>8 \%$ in $22(61 \%)$ of
36 countries/areas (2), a level of chronic infection considered to be highly endemic (1). As of December 2017, all countries/areas in the WPR had completed serosurveys except for Nauru and New Caledonia; seven countries/areas conducted serosurveys before 2009 (Table 2). By December 2017, HBsAg seroprevalence among children aged 5 years declined to $<1 \%$ in $25(69 \%)$ countries/areas based on national serosurveys (Table 2). Notably, China, which has the largest birth cohort 
in the region, was successful in decreasing the prevalence of HBV infection among children to $<0.5 \%$. In Laos, Papua New Guinea, Vietnam, and several of the Pacific Island countries, estimated $\mathrm{HBsAg}$ prevalence among children aged 5 years still exceeds $2 \%$.

\section{Regional Verification of Hepatitis B Control Goal}

In 2007, the WPR established the Hepatitis B Immunization Expert Resource Panel that independently advises on the status of and strategies for achieving the regional hepatitis B control goal. ${ }^{\S}$ The Expert Resource Panel is an interdisciplinary team of 10-15 experts recognized in the field of hepatitis B, and members have expertise in immunization, epidemiology, virology, and hepatology. The Expert Resource Panel convenes verification panels to assess whether countries have met established regional control targets. The verification process includes review of data from nationally representative serosurveys conducted among children aged 5 years, who have already passed through the period of highest risk for perinatal and horizontal transmission of HBV. Panel members also review national and subnational HepB coverage data and supporting evidence of countries' progress in monitoring and targeting high-risk populations including $\mathrm{HBsAg}$-positive mothers and their exposed newborns. As of December 2017, 19 (53\%) of the 36 countries/areas were verified by the Expert Resource Panel as having met the regional $<1 \%$ prevalence target based on serosurvey and vaccination coverage data (Table 2).

\section{Progress Toward Elimination of Mother-to-Child Transmission of HBV}

In 2017, the WPR established a goal for elimination of mother-to-child transmission (MTCT) of HBV by 2030, defined as achievement of a $90 \%$ reduction in new cases of chronic HBV infection, equivalent to $0.1 \% \mathrm{HBsAg}$ seroprevalence among children aged 5 years, as part of the triple elimination framework. Key components of the WPR's strategy to achieve elimination of MTCT of HBV include achieving $\geq 95 \%$ HepB-BD and HepB3 coverage, screening $\geq 95 \%$ of pregnant women for chronic HBV infection, administering hepatitis $B$ immunoglobulin (HBIG) to infants born to $\mathrm{HBsAg}$-positive mothers, and treating pregnant women eligible for treatment with antiviral drugs (5). As of December 2017, 19 (53\%) of 36 countries/areas had developed national plans for viral

\footnotetext{
${ }^{\$}$ At the September 2018 Expert Resource Panel meeting (https://iris.wpro.who. int/bitstream/handle/10665.1/14321/RS-2018-GE-37b-PHL-eng.pdf), two new interim goals were proposed: 1 ) to reduce $\mathrm{HBsAg}$ prevalence to $<1 \%$ among children aged 5 years in all countries and areas by 2025; and 2) in countries and areas that already have $<1 \% \mathrm{HBsAg}$ prevalence in children aged 5 years, to further reduce $\mathrm{HBsAg}$ prevalence to $<0.3 \%$ by 2025 . These are intended to be interim targets for countries to reach the hepatitis B elimination target of $<0.1 \% \mathrm{HBs}$ Ag prevalence among children aged 5 years by 2030 .
}

\begin{abstract}
Summary
What is already known about this topic?

In 1990, chronic hepatitis B virus infection in the World Health Organization Western Pacific Region (WPR) was highly endemic (prevalence $\geq 8 \%$ ).

What is added by this report?

During 2005-2017, regional hepatitis B vaccine birth dose (HepB-BD) and third dose (HepB3) coverage increased from 63\% to $85 \%$ and from $76 \%$ to $93 \%$, respectively. In 2017,15 (42\%) and 18 (50\%) of 36 WPR countries/areas achieved $\geq 95 \%$ HepB-BD and HepB3 coverage, respectively. Chronic hepatitis infection in children declined to $<1 \%$ in 25 (69\%) countries/areas.

What are the implications for public health practice?

Continued commitment and enhanced coordination among programs that offer different hepatitis B prevention interventions are needed to achieve hepatitis B elimination by 2030.
\end{abstract}

hepatitis prevention; $26(70 \%)$ countries/areas reported having established integrated routine antenatal screening programs for HIV and syphilis (data not shown); and 20 (56\%) countries/ areas had a national policy for routine antenatal HBsAg testing (Table 3). However, only two (6\%) countries reported testing $\geq 95 \%$ pregnant women for $\mathrm{HBsAg}$, and eight countries (22\%) reported providing antivirals to infected mothers. In addition to providing timely $\mathrm{HepB}-\mathrm{BD}$ and $\mathrm{HepB} 3$ vaccination for HBV-exposed infants, 10 (28\%) countries/areas administered HBIG to newborns of HBsAg-positive mothers, and seven (19\%) provided postvaccination serologic testing to determine the infection status of exposed infants.

\section{Discussion}

During 2005-2017, the WPR achieved remarkable progress toward the regional hepatitis $\mathrm{B}$ control goal and elimination of MTCT of HBV. HepB has been introduced in all countries/ areas; almost all countries/areas provide universal HepB-BD; coverage with HepB-BD and HepB3 increased by $35 \%$ and $22 \%$, respectively; and 19 (53\%) countries/areas were verified to have achieved the 2017 regional control target by December 2017. This success was corroborated by a 2016 disease modeling study that estimated regional prevalence to be $0.93 \%$ among children born in 2012.9 This model also showed that immunization programs in the region prevented more than 37 million cases of chronic HBV infection, and averted more than seven million deaths related to hepatitis B that would have occurred in the lifetime of children born between 1990

\footnotetext{
Cambodia, Commonwealth of the Northern Mariana Islands, Federated States of Micronesia, French Polynesia, Guam, Niue, and Tokelau presented serosurvey evidence of reaching the $<1 \% \mathrm{HBsAg}$ prevalence target among children aged 5 years after 2016, suggesting that regional prevalence might have further declined.
} 
TABLE 2. Hepatitis B seroprevalence, by country/area — World Health Organization Western Pacific Region, 1976-2017

\begin{tabular}{|c|c|c|c|}
\hline Country/Area & $\begin{array}{c}\text { Year of most recent } \\
\text { hepatitis B serosurvey }\end{array}$ & HBsAg prevalence $(95 \% \mathrm{Cl})$ & $\begin{array}{c}\text { Year of verification of } \\
<1 \% \mathrm{HBsAg} \text { seroprevalence }\end{array}$ \\
\hline American Samoa & 2011 & $0.2 \%$ & 2014 \\
\hline Australia & 2002 & $0.4 \%(0.0 \%-2.2 \%)$ & 2012 \\
\hline Brunei & 2011 & $0.1 \%$ & 2013 \\
\hline Cambodia & 2017 & $0.6 \%(0.3 \%-0.9 \%)^{\dagger}$ & $N S^{\S}$ \\
\hline China & 2014 & $0.3 \%(0.2 \%-0.5 \%)$ & 2012 \\
\hline Commonwealth of Northern Mariana Islands & 2014 & $0.0 \%(0.0 \%-0.5 \%)$ & 2017 \\
\hline Cook Island & 2012 & $0.0 \%$ & 2013 \\
\hline Federated States of Micronesia & 2016 & $0.3 \%(0.1 \%-0.5 \%)$ & $N S^{\S}$ \\
\hline Fiji & $2008^{q}$ & $0.0 \%$ & NS \\
\hline French Polynesia & 2014 & $0 \%(0.0 \%-0.5 \%)$ & 2016 \\
\hline Guam & 2015 & $0.0 \%$ & 2016 \\
\hline Hong Kong (China, SAR) & 2009 & $0.8 \%(0.4 \%-1.2 \%)$ & 2011 \\
\hline Japan & 2010 & $0.2 \%(0.0 \%-0.4 \%)$ & NS \\
\hline Kiribati & 2014 & $3.3 \%(2.4 \%-4.6 \%)$ & NS \\
\hline Laos & 2012 & $1.7 \%(0.8 \%-2.6 \%)$ & NS \\
\hline Macao (China, SAR) & 2003 & $0 \%(0.0 \%-0.7 \%)$ & 2008 \\
\hline Malaysia & 2009 & $0.4 \%(0.2 \%-0.6 \%)$ & 2011 \\
\hline Marshall Islands & 2017 & $1.2 \%(0.6 \%-1.9 \%)$ & UR \\
\hline Mongolia & 2009 & $0.5 \%(0.4 \%-0.7 \%)$ & 2012 \\
\hline Nauru & ND & - & NS \\
\hline New Caledonia & ND & - & NS \\
\hline New Zealand & 2009 & $0.2 \%(0.0 \%-1.2 \%)$ & 2012 \\
\hline Niue & 2015 & $0.0 \%$ & 2017 \\
\hline Palau & 2008 & $0.0 \%$ & 2013 \\
\hline Papua New Guinea & $2012-2013$ & $2.3 \%$ & NS \\
\hline Philippines & 2013 & $0.9 \% * *$ & NS \\
\hline Republic of Korea & 2014 & $0.1 \%$ & 2008 \\
\hline Samoa & 2014 & $0.1 \%$ & NS \\
\hline Singapore & 2010 & $0.3 \%(0.1 \%-0.9 \%)$ & 2015 \\
\hline Solomon Islands & 2016 & $3.1 \%(2.0 \%-4.9 \%)^{\dagger}$ & NS \\
\hline Tokelau & 2014 & $0.0 \%$ & 2016 \\
\hline Tonga & 2005 & $0.8 \%(0.2 \%-2.5 \%)$ & 2012 \\
\hline Tuvalu & 1976 & $11.0 \%$ & NS \\
\hline Vanuatu & 1998 & $3.0 \%$ & NS \\
\hline Vietnam & 2011 & $2.2 \%(1.5 \%-3.1 \%)$ & NS \\
\hline Wallis and Futuna & 2012 & $0.9 \%$ & NS \\
\hline
\end{tabular}

Abbreviations: $\mathrm{Cl}=$ confidence interval; $\mathrm{HBsAg}=$ hepatitis $\mathrm{B}$ surface antigen; $\mathrm{ND}=$ not done; $\mathrm{NS}=$ not submitted to the regional verification commission; $\mathrm{SAR}=$ special autonomous region; $\mathrm{UR}=$ under review by the regional verification commission.

* Verification is done by a regional commission of experts from the Hepatitis B Immunization Expert Resource Panel that determines if the country or area has reached

the target of $<1 \% \mathrm{HBsAg}$ seroprevalence among children aged 5 years.

† Preliminary data.

$\S$ By December 2017, Cambodia and the Federated States of Micronesia had conducted nationally representative serosurveys and were subsequently verified as meeting the $<1 \%$ HBsAg seroprevalence target in 2018.

I Fiji completed a subnational hepatitis B serosurvey in 2008 and is planning its first nationally representative survey for 2019.

** The Philippines conducted a nationally representative serosurvey in 2018 with preliminary results indicating a $0.7 \%$ HBsAg prevalence among children aged 5 years.

and 2014 had hepatitis B vaccination programs not been established (2).

Interventions implemented to increase HepB-BD vaccination coverage included promoting community awareness about the need for HepB vaccination, especially the administration of a timely HepB-BD; building capacity and knowledge of health care staff to administer a timely birth dose; using HepB-BD outside the cold chain; and promoting institutional deliveries (7). WPR countries/areas have extensive experience using the highly heat stable monovalent HepB-BD outside the cold chain in areas that lack a reliable cold chain or have high home birth rates with limited health facility access. This use of the HepB-BD outside the commonly recommended storage temperatures of $35^{\circ} \mathrm{F}-46^{\circ} \mathrm{F}\left(2^{\circ} \mathrm{C}-8^{\circ} \mathrm{C}\right)$ for limited periods under monitored and controlled conditions, has been demonstrated to be safe and effective, with WHO suggesting outside-the-cold-chain use in settings where HepB-BD administration is restricted by access to cold storage (1). HepB-BD use outside the cold chain has been used to increase timely HepB-BD administration by $27 \%$ in Laos, $70 \%$ in China, and $150 \%$ in the Solomon Islands $(7,8)$. Cambodia and China have national policies that encourage pregnant women to deliver in health facilities to reduce maternal and neonatal mortality by ensuring that mothers and newborns are examined by health care professionals within 24 hours of delivery. Institutional delivery also facilitates coordination of postnatal care services 
TABLE 3. Policies and interventions implemented in elimination of mother-to-child transmission of hepatitis B - World Health Organization (WHO) Western Pacific Region (36 countries/areas) 2017

\begin{tabular}{|c|c|c|c|}
\hline \multirow[b]{2}{*}{ Policies/Interventions } & \multicolumn{3}{|c|}{ No. (\%) of areas } \\
\hline & Implemented & $\begin{array}{c}\text { Not } \\
\text { implemented }\end{array}$ & $\begin{array}{l}\text { Data not } \\
\text { available }\end{array}$ \\
\hline National plan for viral hepatitis $^{\dagger}$ & $19(53)$ & $6(17)$ & $11(31)$ \\
\hline $\begin{array}{l}\text { National policy for antenatal } \\
\mathrm{HBsAg} \text { testing }^{\dagger}\end{array}$ & $20(56)$ & $2(6)$ & $14(39)$ \\
\hline $\begin{array}{l}\text { Maternal antivirals given for } \\
\text { EMTCT of hepatitis } B^{\dagger}\end{array}$ & $8(22)$ & $8(22)$ & $20(56)$ \\
\hline $\begin{array}{l}\text { HBIG given to } \\
\text { HBV-exposed infants }{ }^{\dagger}\end{array}$ & $10(27)$ & $6(17)$ & $20(56)$ \\
\hline $\begin{array}{l}\text { Follow-up with PVST for } \\
\text { HBV-exposed infants }\end{array}$ & $7(19)$ & $9(25)$ & $20(56)$ \\
\hline ANC1 $\geq 95 \% \S$ & $13(36)$ & $10(28)$ & $13(36)$ \\
\hline ANC4 $\geq 95 \%{ }^{\S}$ & $1(3)$ & $19(53)$ & $16(44)$ \\
\hline SBA present at $\geq 95 \%$ births $^{\S}$ & $17(47)$ & $10(28)$ & $9(25)$ \\
\hline $\begin{array}{l}\text { Antenatal } \mathrm{HBsAg} \text { testing } \\
\text { coverage } \geq 95 \% \%\end{array}$ & $2(6)$ & $1(3)$ & $33(92)$ \\
\hline HB-BD coverage $\geq 95 \% * *,+\dagger$ & $15(42)$ & $17(47)$ & $2(6)$ \\
\hline HB3 coverage $\geq 95 \%^{* *}$ & $18(50)$ & $16(44)$ & $2(6)$ \\
\hline
\end{tabular}

Abbreviations: $\mathrm{ANC} 1=$ at least 1 antenatal care visit; $\mathrm{ANC} 4=$ at least 4 antenatal care visits; EMTCT = elimination of maternal-to-child transmission; $\mathrm{HBsAg}=$ hepatitis $B$ surface antigen; $\mathrm{HBIG}=$ hepatitis $B$ immunoglobulin; $\mathrm{HBV}=$ hepatitis $B$ virus; $\mathrm{HepB}-\mathrm{BD}=$ birth dose of monovalent hepatitis $B$ vaccine; $\mathrm{HepB}=$ third dose of a hepatitis $B$ containing vaccine; PVST = postvaccination serological testing; SBA = skilled birth attendant; UNICEF = United Nations Children's Fund.

* The Pitcairn Islands is excluded from analysis because it does not report immunization coverage.

† Information collected from countries in preparation for the Midterm review of the Regional Action Plan for Viral Hepatitis in the Western Pacific 20162020, December 13-14, 2018, Manila, Philippines.

$\S$ UNICEF data. Monitoring the situation of children and women; https://data. unicef.org/ updated June 2018, data from 2006-2017.

" China, Wang et al. Bull World Health Organ 2015;93:52-6; Republic of Korea, unpublished study of the liver 2013; Mongolia, reported at the Informal Consultation on Validation of Elimination of Mother-to-child Transmission of HIV, Hepatitis B and Syphilis: Developing the Method for Validating Hepatitis B Elimination, February 27-28, 2018.

** WHO and UNICEF estimates for all 27 countries in the Western Pacific Region, unless otherwise specified; reported coverage for the remaining nine reporting areas and territories in the Western Pacific Region.

${ }^{\dagger}+$ Japan and New Zealand are excluded for this indicator as these countries selectively offer hepatitis B birth dose to newborns of HBsAg-positive mothers or mothers with unknown HBsAg status.

between maternal, neonatal, and child health programs and national immunization programs that can improve timely HepB-BD coverage $(7,9)$.

To reach the global hepatitis $\mathrm{B}$ elimination goal of $\leq 0.1 \%$ $\mathrm{HBsAg}$ prevalence among children aged 5 years by 2030, WPR countries/areas need to achieve elimination of MTCT of HBV, because perinatal transmission accounts for a high proportion of chronic HBV infections among children (1). The triple elimination framework provides guidance for a coordinated delivery of services for immunization, HIV, sexually transmitted infections, and reproductive, maternal, neonatal, and child health to ensure that a timely HepB-BD is administered and high HepB3 coverage is achieved. The framework also provides guidance for implementation of complementary interventions in addition to vaccination to prevent perinatal HBV transmission, including routine testing of pregnant women and timely administration of hepatitis B immunoglobulin to exposed newborns. In addition, the framework suggests possible administration of antiviral drugs to mothers with high viral loads, while awaiting global guidance on its use to prevent MTCT of HBV (5).** In Cambodia, a modeling analysis indicated that offering an integrated package of services through the triple elimination platform could reduce MTCT of HBV by $76 \%$, from $14.1 \%$ to $3.4 \%$; syphilis by $51 \%$, from $9.4 \%$ to $4.6 \%$; and HIV by $8 \%$, from $6.6 \%$ to $6.1 \%$. It could prevent approximately 3,200 infant HBV infections annually at a cost of \$114 USD per disability-adjusted life-year (10).

The WPR has significantly decreased the incidence of chronic HBV infection, with a few countries still requiring programmatic improvement in vaccination to achieve hepatitis $B$ control. As the WPR expands implementation of interventions for elimination of MTCT of HBV, global and regional guidance is needed on 1) the use of monitoring indicators to assess the effect of these interventions on elimination of MTCT, 2) the appropriate frequency of costly serosurveys for verification of achievement of low HBsAg seroprevalence targets, and 3) the use of models to estimate infection prevalence from programmatic data to support countries in their control efforts and the elimination of MTCT verification process.

\footnotetext{
** World Health Organization. Guidelines for the prevention, care, and treatment of persons with chronic hepatitis B infection. https://apps.who.int/iris/ bitstream/handle/10665/154590/9789241549059_eng.pdf.
}

Corresponding author: Joseph Woodring, woodringj@who.int,+329285036370.

\begin{abstract}
${ }^{1}$ Western Pacific Regional Office, Expanded Programme on Immunization, World Health Organization, Manila, Philippines; ${ }^{2}$ Western Pacific Regional Office, HIV, Hepatitis and Sexually Transmitted Infections, World Health Organization, Manila, Philippines; ${ }^{3}$ Global Immunization Division, Center for Global Health, CDC.
\end{abstract}

All authors have completed and submitted the ICMJE form for disclosure of potential conflicts of interest. No potential conflicts of interest were disclosed.

\section{References}

1. World Health Organization. Hepatitis B vaccines: WHO position paperJuly 2017. Wkly Epidemiol Rec 2017;92:369-92.

2. Wiesen E, Diorditsa S, Li X. Progress towards hepatitis B prevention through vaccination in the Western Pacific, 1990-2014. Vaccine 2016;34:2855-62. https://doi.org/10.1016/j.vaccine.2016.03.060

3. World Health Organization, Regional Committee for the Western Pacific. Resolution WPR/RC64.R5: hepatitis B control through vaccination: setting the target. Manila, Philippines: World Health Organization, Regional Committee for the Western Pacific; 2013. https://apps.who.int/ iris/bitstream/handle/10665/137694/WPR_RC064_Res05_2013_en.pdf 
4. World Health Organization. Regional action plan for viral hepatitis in the Western Pacific Region 2016-2020. Manila, Philippines: World Health Organization; 2016. https://iris.wpro.who.int/bitstream/ handle/10665.1/13141/97892906177617_eng.pdf

5. World Health Organization. Regional framework for the triple elimination of mother-to-child transmission of HIV, hepatitis B and syphilis in Asia and the Pacific 2018-2030. Manila, Philippines: World Health Organization; 2018. https://iris.wpro.who.int/bitstream/hand le/10665.1/14193/9789290618553-eng.pdf?ua=1

6. World Health Organization. Global health sector strategy on viral hepatitis 2016-2021. Geneva, Switzerland: World Health Organization; 2016. https://www.who.int/hepatitis/strategy2016-2021/ghss-hep/en/

7. Allison RD, Patel MK, Tohme RA. Hepatitis B vaccine birth dose coverage correlates worldwide with rates of institutional deliveries and skilled attendance at birth. Vaccine 2017;35:4094-8. https://doi. org/10.1016/j.vaccine.2017.06.051
8. Breakwell L, Anga J, Dadari I, Sadr-Azodi N, Ogaoga D, Patel M. Evaluation of storing hepatitis $B$ vaccine outside the cold chain in the Solomon Islands: identifying opportunities and barriers to implementation. Vaccine 2017;35:2770-4. https://doi.org/10.1016/j. vaccine.2017.04.011

9. World Health Organization. WHO recommendations on postnatal care of the mother and newborn. Geneva, Switzerland: World Health Organization; 2014. https://www.who.int/maternal_child_adolescent/ documents/postnatal-care-recommendations/en/

10. Zhang L, Tao Y, Woodring J, et al. Integrated approach for triple elimination of mother-to-child transmission of HIV, hepatitis B and syphilis is highly effective and cost-effective: an economic evaluation. Int J Epidemiol. In press 2019. 